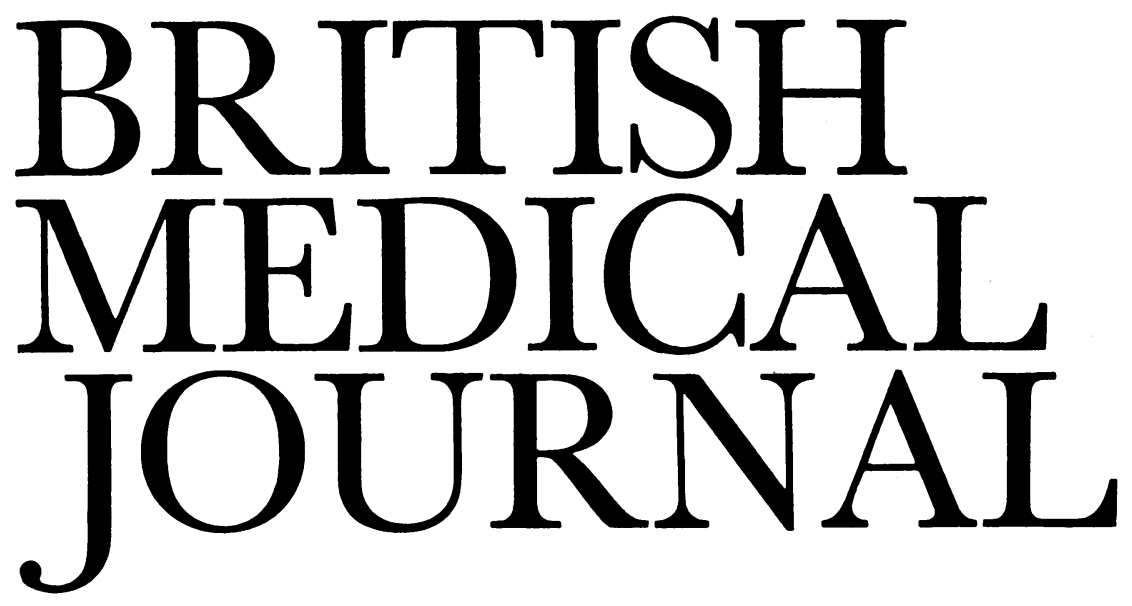

LONDON, SATURDAY 17 MARCH 1979

\title{
Anaesthetic deaths
}

Death as a result of anaesthesia is rare; but when this does occur not uncommonly the patient has been apparently fit, and sometimes there seem to have been failures to maintain proper anaesthetic practice. We need, therefore, to examine the causes of these deaths if we are to avoid similar tragedies in the future.

Surveys over the past 20 years have identified the common problems. The Association of Anaesthetists of Great Britain and Ireland set up a voluntary reporting system to examine deaths resulting from anaesthesia. Two papers, in $1956^{1}$ and $1964,{ }^{2}$ surveyed 1600 reports. Of these, 989 were thought to implicate the anaesthetic. Death was most often attributable to failure to maintain the airway, failure to maintain ventilation, and circulatory failure. Hypovolaemia was a common cause of the circulatory difficulties and was often exacerbated by a (relative) averdose of an intravenous injection of thiopentone. A few deaths were due to failure of anaesthetic apparatus.

In South Australia an anaesthetic mortality committee surveys all deaths associated with anaesthesia. A report of its findings for the years $1969-74^{3}$ suggests that the incidence of death during or after anaesthesia is about 1 in 15000 . One problem it highlighted was cardiac arrest, and the suggested remedy was that more frequent blood pressure monitoring might detect such patients when hypotension preceded the arrest. Wylie ${ }^{4}$ commented on the disastrous consequences of delay in recognising cardiac arrest: in those circumstances permanent neurological damage may be expected in those who survive.

The report of the confidential inquiries into maternal deaths ${ }^{5}$ found that 37 deaths were due to anaesthesia in 1970-2. Obstetrics is known to present special risks, the inhalation of stomach contents being the most important. The other causes included hypoxic cardiac arrest. The important finding is that in three-quarters of the cases there were some avoidable factors. The additional risk of anaesthesia in caesarean section seems to give a death rate of about 1 in 3000 patients.

One of the virtues of the system of reporting maternal deaths is that it does not depend solely on voluntary reporting; the aim is to assess every maternal death. Harrison ${ }^{6}$ has recently described a similar comprehensive survey of all patients anaesthetised in Groote Schuur Hospital, South Africa. In the decade studied 240483 anaesthetics were given and 2442 patients died. Of these deaths, 531 were classified as associated with anaesthesia in that death occurred during or within 24 hours of anaesthesia or before full recovery of consciousness. But in only 53 of the cases was anaesthesia thought to have contributed; the rest were classified as inevitable (135) or a result of other causes (343). The death rate from anaesthesia was 1 in 4537 . The list of causes is depressingly familiar: hypovolaemia, ventilatory failure, failure to maintain airway, cardiac arrest due to drugs or air embolism, and so on. Respiratory failure associated with the use of relaxants was common. The usual combination was severe obstructive airway disease, intestinal obstruction, and the use of neuromuscular blocking drugs.

The striking features in all these series are the preponderance of airway, ventilatory, or circulatory problems. Jaundice after halothane is absent, ${ }^{7}$ but the definition of death from anaesthesia as used by Harrison ${ }^{6}$ would miss that cause: jaundice develops some days after anaesthesia, and the patient would be conscious between the anaesthetic and the development of liver failure.

What are the lessons to be learned ? Death due to anaesthesia is no respecter of persons-it may happen to any patient and in any anaesthetist's practice. Each anaesthetist should determine before, during, and after each anaesthetic that there are no problems with the airway, that ventilation is adequate, and that blood volume and cardiac function are sufficient for the patient's needs. Further training should emphasise fall-back procedures. How should the anaesthetist cope if he fails to secure endotracheal intubation? Tunstall ${ }^{8}$ described one such drill for obstetric anaesthesia. Better monitoring must give earlier warning of cardiac arrest and minimise delay in treating it. Is it now time for all anaesthetised patients in Britain to have their electrocardiogram or pulse continuously displayed?

Further surveys should identify what progress is being made in reducing the death rate of anaesthesia. The Association of Anaesthetists is undertaking a new survey in selected areas in Britain. All deaths during and after operation will be examined to determine the role of anaesthesia. Sadly, the survey will not be extended to look at all the causes of death. The close collaboration of all concerned in obstetrics has made a major contribution to improved maternal care. Was there not a possibility of doing the same for surgery ? In Harrison's series ${ }^{6}$ 
other causes not considered inevitable led to six times as many deaths as anaesthesia.

1 Edwards, G, et al, Anaesthesia, 1956, 11, 194

2 Dinnick, O P, Anaesthesia, 1964, 19, 536

3 Medical fournal of Australia, 1976, 1, 4.

4 Wylie, W D, Annals of the Royal College of Surgeons of England, 1975, 56, 171

${ }^{5}$ Arthure, H, et al, Report on Confidential Enquiries into Maternal Deaths in England and Wales 1970-72. London, HMSO, 1975.

${ }^{6}$ Harrison, G G, British fournal of Anaesthesia, 1978, 50, 1041

${ }^{7}$ Inman, W H W, and Mushin, W W, British Medical fournal, 1978, 2, 1455.

8 Tunstall, M E, Anaesthesia, 1976, 31, 850.

\section{Sex determination and the H-Y antigen}

The process of sex determination in mammals has become at least partially clarified in the last ten years. The correlation found in the late 1950s and the early 1960s between the Y chromosome and the development of testes had shown that normally the indifferent gonad would develop into a testis when a $\mathrm{Y}$ chromosome was present and into an ovary when there was no $\mathrm{Y}$ chromosome. In contrast, in birds and some lower vertebrates the female is heterogametic $(\mathrm{ZW})$ and the male homogametic ( $\mathrm{ZZ})$, and the presence of a W chromosome determines ovarian formation.

Observations made on patients and animals with an aberrant sex chromosome complement (for instance, the XO female in man and the mouse $\mathrm{e}^{1-3}$ ) or where the phenotypic sex does not agree with the genetic sex (Sxr in the mouse, the " $P$ " gene in the goat, ${ }^{5} \mathrm{Tfm}$ in the mouse and man, ${ }^{6} \mathrm{XY}$ females in the wood lemming, ${ }^{7} \mathrm{XY}$ pure gonadal dysgenesis in man, ${ }^{8}$ $\mathrm{XX}$ human males, ${ }^{8} \mathrm{XX}$ true hermaphrodites, and $\mathrm{XX} / \mathrm{XY}$ bovine $^{9}$ and murine chimeras ${ }^{6}{ }^{10}$ ) suggested that autosomal sexlimited or sex-linked genes affecting sex determination were fairly widespread among different animal species.

By 1970, while it was clear that a Y chromosome was necessary to mediate testicular development, it was still uncertain how the $\mathrm{Y}$ chromosome carried out this function, and the search for a factor controlled by a Y-linked gene intensified. One possible candidate was the H-Y antigen, a weak transplantation antigen that had been discovered in $1955,{ }^{11-13}$ when it was shown that within certain highly inbred strains of mice grafts from males to females were rejected whereas grafts exchanged between other sex combinations were uniformly accepted. In 1971 the $\mathrm{H}-\mathrm{Y}$ antigen was identified serologically using a sperm cytoxicity test, and with the development of other and more satisfactory serological tests ${ }^{121415}$ some of the problems associated with the detection of this antigen have been overcome.

In most cases the presence of the $\mathrm{H}-\mathrm{Y}$ antigen is necessary to guarantee the masculinisation of the indifferent gonad. The presence of the antigen is usually-but not invariablycorrelated with the presence of a $\mathrm{Y}$ chromosome. There are exceptions: for instance, no $\mathrm{Y}$ chromosome can be detected in $\mathrm{H}$-Y-positive $\mathrm{XX}$ males, true hermaphrodites, and pseudohermaphrodites in man, ${ }^{1617}$ the mouse, ${ }^{18}$ and the dog. ${ }^{19}$ Various hypotheses have been postulated to explain these findings ranging from translocation of the $\mathrm{Y}$ chromosome material to the presence of $\mathrm{X}$-linked or autosomal modifier genes. The reverse also occurs: $\mathrm{XY}$ females with pure gonadal dysgenesis ${ }^{20}$ are $\mathrm{H}-\mathrm{Y}$ negative, and nearly half of the pheno- typic females of the wood lemming studied have been shown to have $\mathrm{XY}$ sex chromosomes and yet to be $\mathrm{H}-\mathrm{Y}$ negative. ${ }^{21}$ In the latter case whether or not $\mathrm{XY}$ animals are $\mathrm{H}-\mathrm{Y}$ positive seems to determine whether they develop testes and become normal males; if they are $\mathrm{H}-\mathrm{Y}$ negative they do not develop testes and become females. The postulated explanation is that a mutation at an $\mathrm{X}$-linked locus has blocked the expression of the $\mathrm{H}-\mathrm{Y}$ antigen-which implies that it requires at least two loci for its control. ${ }^{21}$ This, taken together with other evidence, suggests that in normal circumstances the structural $\mathrm{H}-\mathrm{Y}$ locus may not be situated on the $\mathrm{Y}$ chromosome but is in fact on the $\mathrm{X}$ chromosome or perhaps on an autosome. Nevertheless, the $\mathrm{H}-\mathrm{Y}$ locus may be controlled by a regulator gene on the $\mathrm{Y}$ chromosome whose function may become translocated or taken over by mutant genes.

The main question now remaining to be answered is whether the $\mathrm{H}-\mathrm{Y}$ antigen is the cell surface component which causes the indifferent gonad to masculinise or whether it is produced by the male as a result of masculinisation of the indifferent gonad under the influence of some other factor controlled by the $\mathrm{Y}$ chromosome.

The most likely hypothesis seems to be that the $\mathrm{H}-\mathrm{Y}$ antigen is the substance which causes the indifferent gonad in the heterogametic sex to develop to testes in XY mammals or to an ovary in ZW birds. The supporting evidence may be summarised as follows. Firstly, the antigen is highly conserved in evolution, cross-reacting throughout the higher vertebrates at least down to the fish and amphibia. ${ }^{22}{ }^{23}$ Secondly, the H-Y antigen can be found on half of eight-cell embryos in the blastocyst. ${ }^{24}$ Thirdly, it has been mapped close to the centromere on the short arm of the human Y chromosome. ${ }^{25}$ Fourthly, the XY cells in the predominantly sex-reversed gonads of the bovine freemartin ${ }^{26}$ and XX gonadal cells which become sertoli and Leydig cells in chimeric testes of the mouse have been shown to be $\mathrm{H}-\mathrm{Y}$ positive ${ }^{27}$ and $\mathrm{XX}$ sex-reversed males in the mouse and man have been shown to be $\mathrm{H}-\mathrm{Y}$ positive. ${ }^{18}$ Fifthly, a series of cellular reaggregation experiments $^{28} 29$ have shown that when free cell suspensions of newborn testicular cells were lysostripped by an excess of $\mathrm{H}-\mathrm{Y}$ antibody the cells reaggregated to form structures like ovarian primordial follicles. Conversely, a free suspension of bovine fetal ovarian cells exposed to $\mathrm{H}-\mathrm{Y}$ antigen reaggregated to form seminiferous tubule-like structures ${ }^{30}$ Finally, some more recent experiments ${ }^{23}$ have suggested that testicular organogenesis depends on two components-the ubiquitously expressed $\mathrm{H}-\mathrm{Y}$ antigen and its specific receptors, which are expressed by gonadal cells of both sexes. It is only the H-Y antigen expression that is confined to the heterogametic sex. All the biological activities of the $\mathrm{H}-\mathrm{Y}$ antigen have been found to reside in a small peptide chain of molecular weight 20000 , which has been defined as the $\mathrm{H}-\mathrm{Y}$ antigen active site.

In conclusion, then, the evidence suggests that the Y-chromosome acts on testicular organogenesis through a Y-linked gene locus, which mediates the production of the $\mathrm{H}-\mathrm{Y}$ antigen either by regulating a structural locus situated elsewhere in the genome or from a Y-linked structural locus itself. This antigen is ubiquitous and highly conserved during evolution and controls gonadal determination in the heterogametic sex.

\footnotetext{
${ }^{1}$ Hamerton, J L, Nature (London), 1968, 219, 910.

${ }^{2}$ McFeely, R A, Hare, W C D, and Biggers, J D, Cytogenetics, 1967, 6, 242. ${ }^{3}$ Cattanach, B M, Genetical Research, 1962, 3, 487.

4 Cattanach, B M, Pollard, C E, and Hawkes, S G, Cytogenetics, 1971, 10, 318.

${ }^{5}$ Hamerton, J L, et al,fournal of Reproduction and Fertility, 1969, suppl 7, p 25.
} 